\title{
CHARACTERIZATION OF AIRBORNE PLUTONIUM-BEARING PARTICLES FROM A NUCLEAR FUEL REPROCESSING PLANT
}

by

S. Marshall Sanders, Jr.

Approved by

E. L. Albenesius, Research Manager

Environmental Effects Division

Publication Date: November 1977

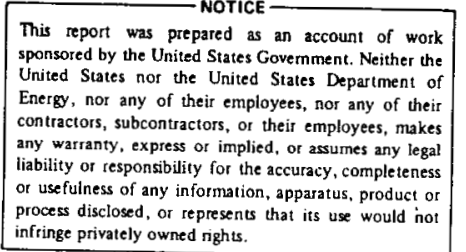

process disclosed, or represents that its use would not

E. I. dU PONT de NEMOURS and COMPANY SAVANNAH RIVER LABORATORY AIKEN, SOUTH CAROLINA 29801

PREPARED FOR THE U.S. DEPARTMENT OF ENERGY UNDER CONTRACT AT(07-2)-1

This document is

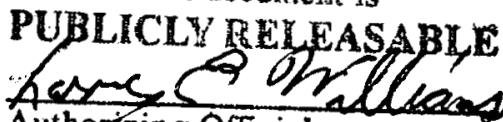

Authorizing Official

Date: $01 / 16 / 2007$ 


\section{DISCLAIMER}

This report was prepared as an account of work sponsored by an agency of the United States Government. Neither the United States Government nor any agency Thereof, nor any of their employees, makes any warranty, express or implied, or assumes any legal liability or responsibility for the accuracy, completeness, or usefulness of any information, apparatus, product, or process disclosed, or represents that its use would not infringe privately owned rights. Reference herein to any specific commercial product, process, or service by trade name, trademark, manufacturer, or otherwise does not necessarily constitute or imply its endorsement, recommendation, or favoring by the United States Government or any agency thereof. The views and opinions of authors expressed herein do not necessarily state or reflect those of the United States Government or any agency thereof. 


\section{DISCLAIMER}

Portions of this document may be illegible in electronic image products. Images are produced from the best available original document. 


\section{ABSTRACT}

The elemental compositions, sizes, structures, and ${ }^{239} \mathrm{Pu}$ contents were determined for 299 plutonium-bearing particles isolated from airborne particles collected at various locations in the exhaust from a nuclear fuel reprocessing facility. These data were compared with data from natural aerosol particles. Most of the collected particles were composed of aggregates of crustal materials. Seven per cent of the particles were organic and three per cent were metallic, viz., iron, chromium, and nickel. High enrichment factors for titanium, manganese, chromium, nickel, zinc, and copper were evidence of the anthropic nature of some of the particles. The amount of plutonium in most particles was very small (less than one femtocurie of ${ }^{2{ }^{y}} \mathrm{Pu}$ ). Plutonium concentrations were determined by the fission track counting method. Only one particle contained sufficient plutonium for detection by electron microprobe analysis. This was a $1-\mu \mathrm{m}$-diameter particle containing $73 \% \mathrm{PuO}_{2}$ by weight (estimated to be $170 \mathrm{fCi}$

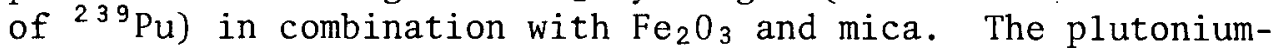
bearing particles were generally larger than natural aerosols. The geometric mean diameter of those collected from the mechanical line exhaust point where plutonium is converted to the metal, was larger than that of particles collected from the wet cabinet exhaust $(13.7 \mu \mathrm{m}$ vs. $4.6 \mu \mathrm{m})$. Particles from the mechanical line also contained more plutonium per particle than those from the wet cabinets. The amount of plutonium per particle decreased with the distance of each sampling point from the mechanical line which is considered the major source of plutonium contamination in the reprocessing facility. 


\section{CONTENTS}

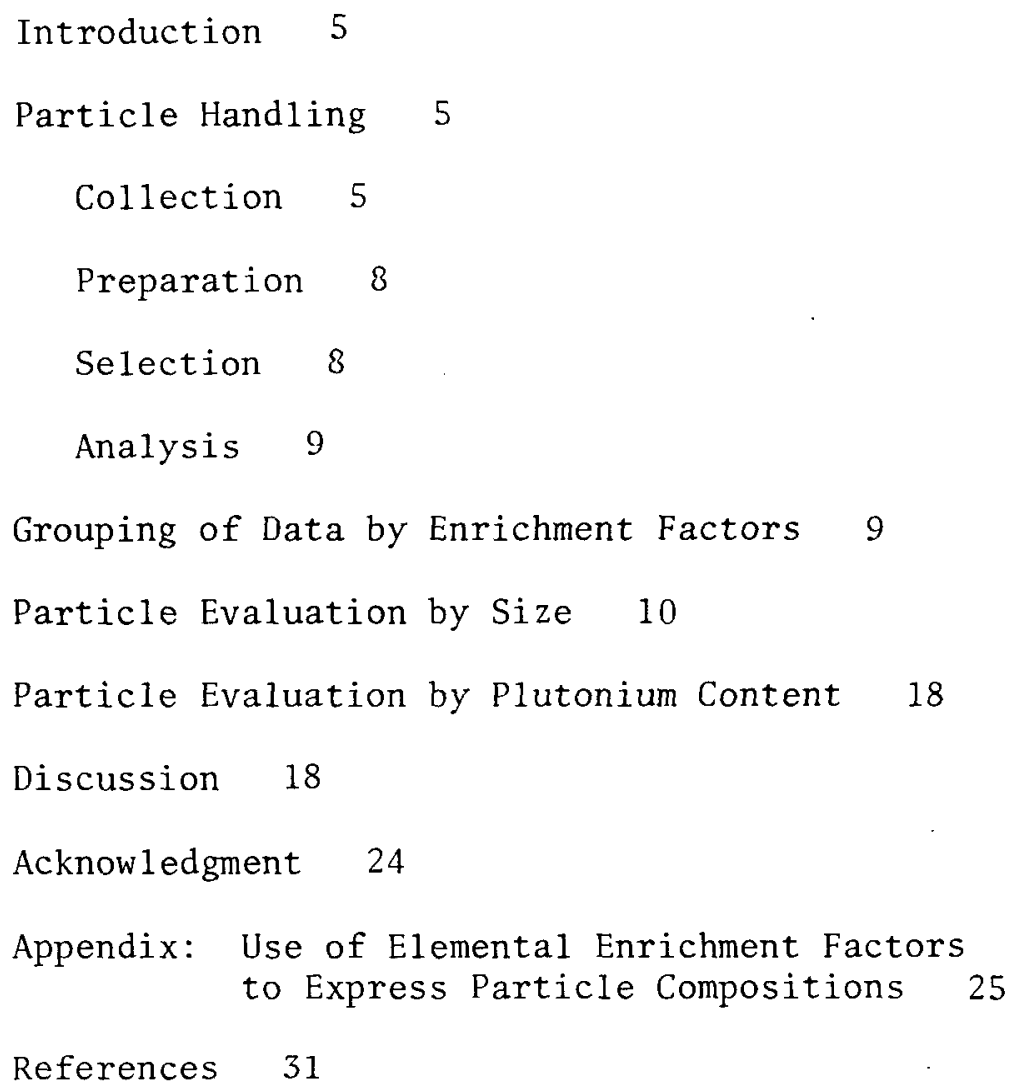




\section{LIST OF FIGURES}

1 Exhaust Systems from JB-Line 6

2 Size Distribution Flots for Natural and Collected Particles 13

3 Frequency Distribution of Diameters of Particles Collected from System II 15

4 Distribution of the Number of Tracks per Particle for Particles Collected from Sampling Points A, B, and C in System II 20

5 Distribution of the Number of Tracks per Particle for Particles Collected from the Mechanical Line (Sampling Point A), Wet Cabinets, and Room Air 21

\section{LIST OF TABLES}

1 Source of Particles Selected for Analysis 7

2 Comparison of Analyses of Particles from Systems I and II 11

3 Comparison of Analyses of Particles from Sampling Points A, B, C, and D of System II

4 Comparison of Size Distributions of Particles from Systems I and II with Natural Aerosols 14

5 Distributions of Particle Diameters in Systems I and II 17

6 Distribution of Fission Tracks among Plutonium-Bearing Particles Collected from Sampling Points A, B, and C 19

7 Distribution of Fission Tracks among Plutonium-Bearing Particles from Various Sources in Systems I and II 22

A-1 Elemental Concentrations in Average Crustal Rock and Geometric Mean Enrichment Factors of Various Aerosols 28 


\section{CHARACTERIZATION OF AIRBORNE PLUTONIUM-B EARING PARTICLES FROM A NUCLEAR FUEL REPROCESSING PLANT}

\section{INTRODUCTION}

Nuclear fuel reprocessing facilities at the Savannah River Plant release to the atmosphere minute quantities $(<1 \mathrm{mCi} / \mathrm{yr})$ of ${ }^{2}{ }^{39} \mathrm{Pu}$ in particulate form. To determine the source and subsequent environmental behavior of this long-lived radionuclide, airborne particles were collected from nine locations in the two systems which exhaust air from the plutonium finishing operation (JB-Line) in Building 221-F. Particles bearing plutonium were identified, isolated from other collected particles, and characterized as to size, morphology, elemental composition, and radioactive properties.

\section{PARTICLE HANDL ING}

\section{Collection}

Particles were collected from air in both exhaust systems in JB-Line. A schematic diagram of these systems is given in Figure 1. System I takes room air from inside wet cabinets (where plutonium is in solution) and from work areas exhausts it via the JB-Line stack. ${ }^{1}$ System II takes air from the mechanical line (where plutonium is handled in metallic form) and exhausts it via the $291-F$ stack. In System I, samples were taken of unfiltered cabinet air from the fifth and sixth levels (Sampling Points 29 and 30 , respectively), of filtered air from both locations (Sampling Point 27), and unfiltered room air from the fifth level (Sampling Point 23), and of air at the 156-foot level of JB-Line stack (Sampling Point 28). In System II, samples were taken of mechanical line air from just beyond the first high-efficiency, particulate air (HEPA) filters located in back of the cabinets (Sampling Point A or 31); of the combined air from the mechanical line, air sample exhaust, furnace off-gas vessel vent, process vacuum system, and air dryer system after the second HEPA filter (Sampling Point B or 26); of the air leaving the sand filter which also contained air from the off-gas system of Building $772-\mathrm{F}$, the process vessel vent, and Building 221-F canyons (Sampling Point $C$ ); and of air from the 50-foot level in the $291-\mathrm{F}$ stack where air from the sand filter mingles with that from A-Line and other sources (Sampling Point D). Air was sampled almost continuously at all locations (except at Sampling Point A) during June 1975 for System I and October 1975 for System II. The level of radioactivity at Sampling Point A 
was so high that samples were collected only during the first two days. The periods during which System I samples were taken are listed in Table 1A; those for System II are listed in Table 1B.

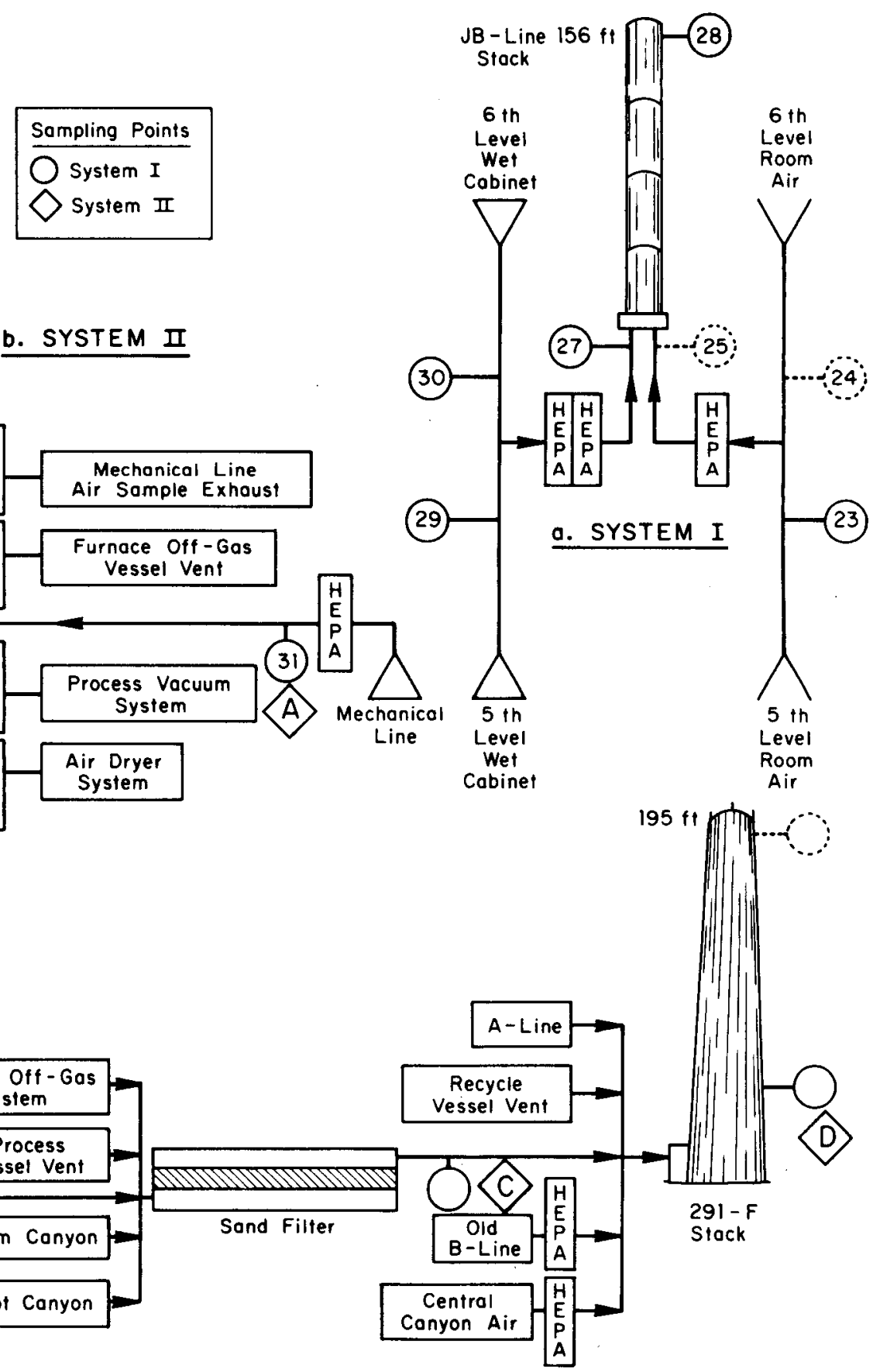

FIGURE 1. Exhaust Systems from JB-Line 
TABLE 1

Source of the Particles Selected for Analysis

A. System I

\begin{tabular}{|c|c|c|c|}
\hline Scmple Collected & $\begin{array}{l}\text { Membrane } \\
\text { Filter } \\
\text { Number }\end{array}$ & $\begin{array}{l}\text { Days on } \\
\text { Which Filter } \\
\text { was Used }\end{array}$ & $\begin{array}{l}\text { Number of } \\
\text { Particles } \\
\text { Analyzed }\end{array}$ \\
\hline $\begin{array}{l}\text { Unfiltered wet } \\
\text { cabinet exhaust }\end{array}$ & $\begin{array}{l}1 \\
2 \\
3 \\
4 \\
5 \\
6 \\
7\end{array}$ & $\begin{array}{l}1 \\
2 \\
9 \\
14 \\
15 \\
98 \\
99-103\end{array}$ & $\begin{array}{l}3 \\
5 \\
3 \\
5 \\
8 \\
6 \\
8 \\
38\end{array}$ \\
\hline $\begin{array}{l}\text { Unfiltered wet } \\
\text { cabinet exhaust }\end{array}$ & $\begin{array}{l}1 \\
2 \\
3\end{array}$ & $\begin{array}{l}98 \\
99-103 \\
107-113\end{array}$ & $\begin{array}{r}4 \\
9 \\
54 \\
67\end{array}$ \\
\hline $\begin{array}{l}\text { Unfiltered room } \\
\text { air exhaust }\end{array}$ & $\begin{array}{l}1 \\
2\end{array}$ & $\begin{array}{l}94-98 \\
99-103\end{array}$ & $\begin{array}{l}3 \\
3 \\
6\end{array}$ \\
\hline
\end{tabular}

B. System II

Scompling Point: A $B \quad B \quad C \quad$ D

Days on which

Filter was Used Particle Ratios, no. analyzed/no. identified

1

2

$\left.\begin{array}{l}143 / 5.2 \times 10^{5} \\ -/-a\end{array}\right\} 3 / 3 \quad 0 / 0 \quad n$

3-6

$7-10$

$1 / 1$

$4 / 4 \quad 0 / 0^{c, g}$

$11-13$

$6 / 12$

$0 / 0^{c} \quad 8 / 8^{g}$

$11-13$

$0 / 3^{c} \quad 7 / 7^{c} \quad n$

$14-16$

$1 / 1^{c} \quad 0 / 0^{c} \quad n$

$17-20$

$0 / 1^{c} \quad 2 / 2^{c, g} \quad n$

$21-23$

$0 / 39 \quad 0 / 1 \quad n$

$24-27$

$0 / 106 \quad 3 / 3 \quad n$

$28-31$

Total

$\underline{0 / 92} \quad \frac{0 / 3}{16 / 17} \quad \frac{n}{8 / 8}$

a. - = Filters from which no particles were selected for microprobe analysis.

$c=$ Film cloudy making identification of particles difficult.

$g=$ Film grainy making identification of particles difficult.

$n=$ Filter nitrated by stack $\mathrm{NO}_{2}$ making identification of particles in film impossible. 
The particles selected for analysis came from 23 filters used to sample the exhaust. Twelve of these filters contained 111 particles from System I as previously reported. ${ }^{1}$ One filter contained 10 particles from System I which were not among the 111 particles previously reported. Ten filters contained 178 particles from System II. A summary of the sources of selected particles is given in Table 1 .

\section{Preparation}

Samples of exhaust air were filtered at $61 / \mathrm{min}$ through 47-mm diameter, polycarbonate, membrane filters having $0.1-\mu \mathrm{m}-$ diameter pores. Each filter was dissolved in $3 / 4 \mathrm{ml}$ of $40 \%(\mathrm{v} / \mathrm{v})$ 1,2-dichloroethane in dichloromethane. This solution was evaporated on a two-inch-square glass plate to form a clear polycarbonate film containing the particles. An acrylic frame was fused to the film for support, and the glass plate was removed.

The cast film was irradiated with a measured thermal neutron fluence in the order of $8.6 \times 10^{14}$ neutrons $/ \mathrm{cm}^{2}$. Fission fragments produced tracks which radiated from imbedded particles containing fissionable material. To make these tracks visible with an optical microscope, the polycarbonate film was etched for ten minutes in $6 \mathrm{~N} \mathrm{NaOH}$ at $50^{\circ} \mathrm{C}$.

Particles having fission-fragment tracks were located under a microscope. Microscopic squares of polycarbonate containing single selected particles were excised from the film. These polycarbonate squares were placed on a polished beryllium samplemounting block that was one inch in diameter and scribed with a grid of numbered one-mm squares. The tracks in each polycarbonate square were photographed. The polycarbonate was then washed from around the particle with 1,2-dichloroethane solvent using microbrushes constructed from glass capillary tubes and glass wool.

Free from polycarbonate, each particle mounted on the beryllium sample-mounting block was again photographed. These photographs were used to determine the particle diameters and structures and to locate the particle during electron microprobe analysis. For better resolution, some particles were also photographed with a scanning electron microscope.

\section{Selection}

The particles were classified into plutonium-bearing and non-plutonium-bearing categories. Only plutonium-bearing particles were selected for characterization. 
Data on a total of 299 plutonium-bearing particles has thus far been collected. A previous report ${ }^{1}$ covered 111 of these particles collected from system $I$. To this number, data on 10 particles from unfiltered room air exhaust in System I have been added. A total of 178 plutonium-bearing particles from System II have also been analyzed. Twenty of this latter group contained no elements having an atomic number greater than ten. They could be observed optically, but produced no detectable x-rays under the electron microprobe and thus were judged to be organic in composition. In general, these were large particles. Fifteen were between 11 and $45 \mu \mathrm{m}$ in diameter. Eighteen were collected from Sampling Point A and two from Sampling Point C. Because a method for the detection and identification of organic constituents of particles was not available, these particles were not included in this study.

\section{Analysis}

The plutonium-bearing particles, mounted on beryllium blocks, were analyzed with an electron microprobe. The analyses were made at Arizona State University in Tempe, Arizona, with a Cameca MS46 electron microprobe equipped with four crystal, wave-lengthdispersive spectrometers (take-off angle of $18^{\circ}$ ) and an energydispersive analyzer.

Analytical data included measurements of $x$-ray intensities and estimates of particle size and shape. These data, along with estimated average densities, were used in the FRAME computer program ${ }^{2}$ as modified for particles work by Armstrong. ${ }^{3}$ These calculations gave the composition of each particle in both elements and oxide weight percents. Oxygen was not measured as such; elements were simply assumed to be present in the oxide form.

\section{GROUPING OF DATA BY ENRICHMENT FACTORS}

A simple tabulation of the elemental weight percents found in the 279 plutonium-bearing particles would reveal little of their origin or distinctive characteristics as a group, nor would it enable a comparison of their compositions with that of other aerosols and sources. The composition of each particle, when expressed as elemental weight percent, appeared to be unique, containing unrelated combinations of 20 different elements not resembling the composition of any likely source.

The results were therefore expressed in terms of "enrichment factors" (dimensionless ratios of elemental concentrations), which enabled the intercomparison of the compositions of plutonium-bearing 
particles with other atmospheric aerosols and the intracomparison among particles collected from different sampling points. A definition of enrichment factors and an explanation of their development and application in this work is given in the Appendix to this report.

To compare the chemical composition of the particles collected from Systems I and II with each other and with the average for global crustal aerosol, the particle analyses were grouped according to the level of the enrichment factors. Four groups were established for each element using the elemental concentration data in Table A-1 of the Appendix. The first group contained those particles which contained no detectable amounts of the element sought. The second group contained detectable amounts with enrichment factors less than one standard deviation below the geometric mean enrichment factor, $\overrightarrow{\mathrm{EF}}_{\mathrm{g}} / \mathrm{sg}$. The third group contained particles with enrichment factors between the lower and upper limits of one standard deviation from the geometric mean enrichment factor, $\overline{\mathrm{EF}}_{\mathrm{g}} / \mathrm{s}_{\mathrm{g}}$ and $\overline{\mathrm{EF}}_{\mathrm{g}} \cdot \mathrm{s}_{\mathrm{g}}$, respectively. The fourth group contained enrichment factors greater than one standard geometric mean enrichment factor, $\overline{\mathrm{EF}} \cdot \mathrm{sg}$. The third column of Table 2 gives the percent of the particles analyzed which gave. positive analyses for each element. The fourth, fifth, and sixth columns of Table 2 contain the percent of those having positive analyses which had enrichment factors less than, between, and more than the lower and upper limits of the geometric standard deviation.

To compare the chemical composition of particles collected at the various sample points in System II with each other and global crustal aerosol (Table A-1), this process was repeated and the results are listed in Table 3 .

Particles having no detectable amounts of an element were not counted with those with enrichment factors less than the lower limit for the geometric standard deviation $(\mathrm{sg})$ because there can be no zero or negative concentration of enrichment factor values in $\log$-normal frequency distributions. Thus the size of the three groups are expressed as the percent of the particles giving positive analyses, rather than the percent of the total number of particles.

\section{PARTICLE EVALUATION BY SIZE}

In this study, particles were selected for analysis based on the number of observed fission-fragment tracks. There being many more particles than could be analyzed, those having three or four tracks were generally passed over in favor of those surrounded by 50 or more tracks. The selection of particles for analysis, however, was not biased by physical size. The size of the particles was 
TABLE 2

Comparison of Analyses of Particles from Systems I and II

\begin{tabular}{|c|c|c|c|c|c|}
\hline & & & $\%$ of $F$ & sitive $A n$ & zyses ${ }^{\alpha}$ \\
\hline Element & System & $\begin{array}{l}\text { Positive } \\
\text { Analyses, \% }\end{array}$ & $\begin{array}{l}\text { Less } \\
\text { Than }^{b}\end{array}$ & Withinc & $\begin{array}{l}\text { Greater } \\
\text { Than }\end{array}$ \\
\hline $\mathrm{Si}$ & I & 100 & 47 & 24 & 29 \\
\hline & II & 98 & 33 & 37 & 29 \\
\hline A I & 1 & 84 & 0 & 100 & 0 \\
\hline & II & 76 & 0 & 100 & 0 \\
\hline $\mathrm{Fe}$ & I & 93 & 14 & 35 & 51 \\
\hline & I I & 99 & 31 & 25 & 44 \\
\hline $\mathrm{Ca}$ & I & 70 & 53 & 30 & 17 \\
\hline & II & 59 & 20 & 44 & 37 \\
\hline $\mathrm{Na}$ & I & 70 & 13 & 72 & 15 \\
\hline & II & 55 & 14 & 63 & 23 \\
\hline K & I & 90 & 56 & 30 & 14 \\
\hline & II & 74 & 19 & 50 & 31 \\
\hline $\mathrm{Mg}$ & I & 51 & 24 & 59 & 17 \\
\hline & II & 61 & 34 & 53 & 14 \\
\hline $\mathrm{Ti}$ & I & 74 & 20 & 17 & 65 \\
\hline & II & 44 & 12 & 4 & 84 \\
\hline $\mathrm{P}$ & II & 2 & 0 & 33 & 67 \\
\hline $\mathrm{Mn}$ & I & 10 & 0 & 0 & 100 \\
\hline & I I & 6 & 10 & 10 & 80 \\
\hline $\mathrm{Ba}$ & I I & 1 & 0 & 0 & 100 \\
\hline s. & I & 17 & 47 & 47 & 5 \\
\hline & I I & 58 & 24 & 58 & 18 \\
\hline $\mathrm{Cl}$ & I & 34 & 13 & 67 & 21 \\
\hline & II & 46 & 3 & 50 & 47 \\
\hline $\mathrm{Cr}$ & I & 53 & 0 & 18 & 82 \\
\hline & II & 26 & 0 & 5 & 95 \\
\hline $\mathrm{Ni}$ & I & 56 & 2 & 25 & 73 \\
\hline & II & 2 & 0 & 0 & 100 \\
\hline $\mathrm{Zn}$ & I & 64 & 4 & 41 & 55 \\
\hline & II & 54 & 12 & 32 & 56 \\
\hline $\mathrm{Cu}$ & I & 36 & 12 & 37 & 51 \\
\hline & I I & 20 & 7 & 29 & 65 \\
\hline$w$ & I & 1 & 0 & 0 & 100 \\
\hline & II & 1 & 0 & 0 & 100 \\
\hline $\mathrm{Cd}$ & I I & 1 & 0 & 0 & 100 \\
\hline
\end{tabular}

a. The percent of the positive analyses less than, within, and greater than one geometric standard deviation of the global geometric mean enrichment factor.

b. $E F<\overline{E F}_{\mathrm{g}} / s_{\mathrm{g}}$

c. $\overline{E F} \bar{g}_{g} / s_{g} \leqslant E F \leqslant \overline{E F}_{g} \cdot s_{g}$

d. $E F>\overline{E F}_{\mathrm{g}} \cdot \mathrm{s} g$ 
TABLE 3

Comparison of Analyses of Particles from Sampling Points A, B, C, and D of System II

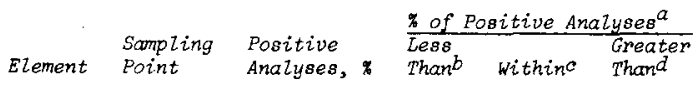

Si

$\begin{array}{ll}\text { A } & \\ \text { B } & \\ \text { C } & 100 \\ \text { D } & 100\end{array}$

A]

$\begin{array}{ll}\mathrm{A} & 79 \\ \mathrm{~B} & 73 \\ \mathrm{C} & 50 \\ \mathrm{D} & \mathbf{8 8}\end{array}$

99
82
100
100
79
73
50
88

$\begin{array}{rrr}35 & 33 & 32 \\ 11 & 56 & 33 \\ 21 & 71 & 7 \\ 50 & 25 & 25 \\ & & \\ 0 & 100 & 0 \\ 0 & 100 & 0 \\ 0 & 100 & .0 \\ 0 & 100 & 0\end{array}$

$\mathrm{Fe}$

$\begin{array}{rr}\text { A } & 98 \\ \text { B } & 100 \\ \text { C } & 100 \\ \text { D } & 100\end{array}$

$\mathrm{Ca}$

$\begin{array}{ll}\text { A } & 56 \\ \text { B } & 91 \\ \text { C } & 57 \\ \text { D } & 63\end{array}$

$\mathrm{Na}$

$\begin{array}{ll}\text { A } & 55 \\ \text { B } & 91 \\ \text { C } & 57\end{array}$

K

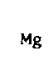

$\mathrm{Mg}$

$\mathrm{Ti}$

$\begin{array}{ll}\text { A } & 42 \\ \text { B } & 64 \\ \text { C } & 50 \\ \text { D } & 38\end{array}$

$\begin{array}{lll}\text { P } & \text { A } & 2 \\ \text { C } & 7\end{array}$

Mn

$\begin{array}{rr}\text { A } & 7 \\ \text { B } & 9 \\ \text { D } & 13\end{array}$

Ba $\quad \begin{array}{ll}\text { A } & 1 \\ & \text { B }\end{array}$

$\mathrm{Cl}$

$\mathrm{Cr}_{\mathrm{r}}$

Ni $\quad B \quad 9$

Zn

$\mathrm{Cu}$

$\begin{array}{ll}\text { A } & 22 \\ \text { B } & 27 \\ \text { C } & \end{array}$

W A

$c d$

a. The percent of the positive analyses less than, within, and greater than one geometric standard deviation of the global geometric mean enrichment factor.

b. $\mathrm{EF}<\overline{\mathrm{EF}} \overline{\mathbf{g}}_{\mathrm{g}} / \mathrm{s}$

c. $\overline{\mathrm{EF}}_{\mathrm{g}} / \mathrm{s}_{\mathrm{g}} \leqslant \mathrm{EF} \leqslant \overline{\mathrm{EF}}_{\mathrm{g}} \cdot \mathrm{s}_{\mathrm{g}}$

d. $\mathrm{EF}>\overline{\mathrm{EF}}_{\mathrm{g}} \cdot \mathrm{s} \mathrm{g}$. 
not measured until after the particles had been mounted and the polycarbonate film containing the tracks dissolved. Thus the size distribution of the analyzed particles is indicative of the size distribution of particles in the aerosol carrying most of the plutonium.

Cumulative frequency plots were constructed for particles from Systems I and II. Particles in each system were first ranked in order of their approximate diameter in $\mu \mathrm{m}$ from the smallest to the largest. A list of the number of particles having successively larger diameters was made. A cumulative total of the number of particles at increasing diameter segments was calculated and then normalized by dividing by the total number of particles from each system. This gave the fraction of the particles having a diameter equal to or smaller than any particular diameter. Table 4 lists the particle diameters in $\mu \mathrm{m}$; and, in Columns 3 and 4 , the fraction of the particles having diameters equal to or less than each diameter measured in Systems I and II, respectively. These fractions are also plotted on the logarithmic probability graph given in Figure 2 .

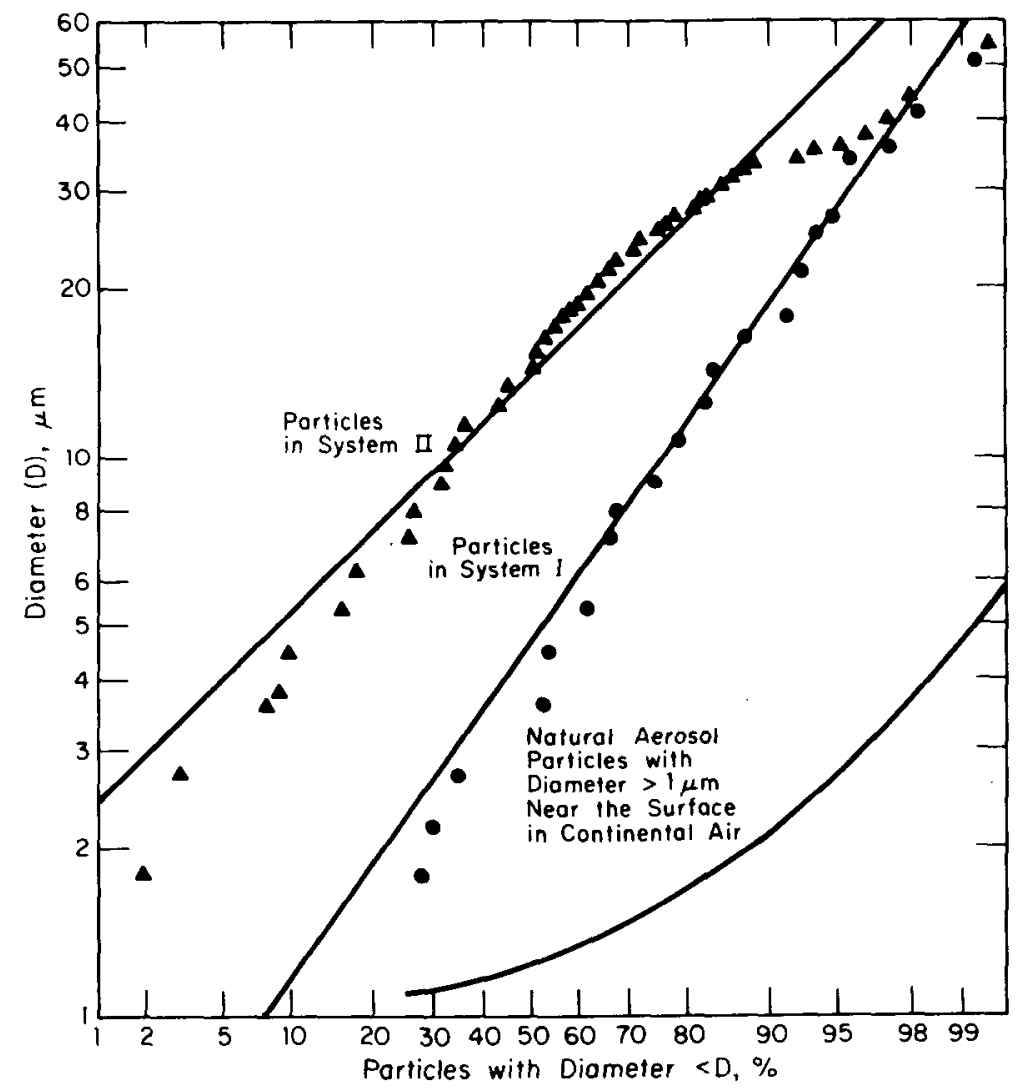

FIGURE 2. Size Distribution Plots for Natural and Collected Particles 
TABLE 4

Comparison of Size Distributions of Particles from Systems I and II with Natural Aerosols ${ }^{a}$

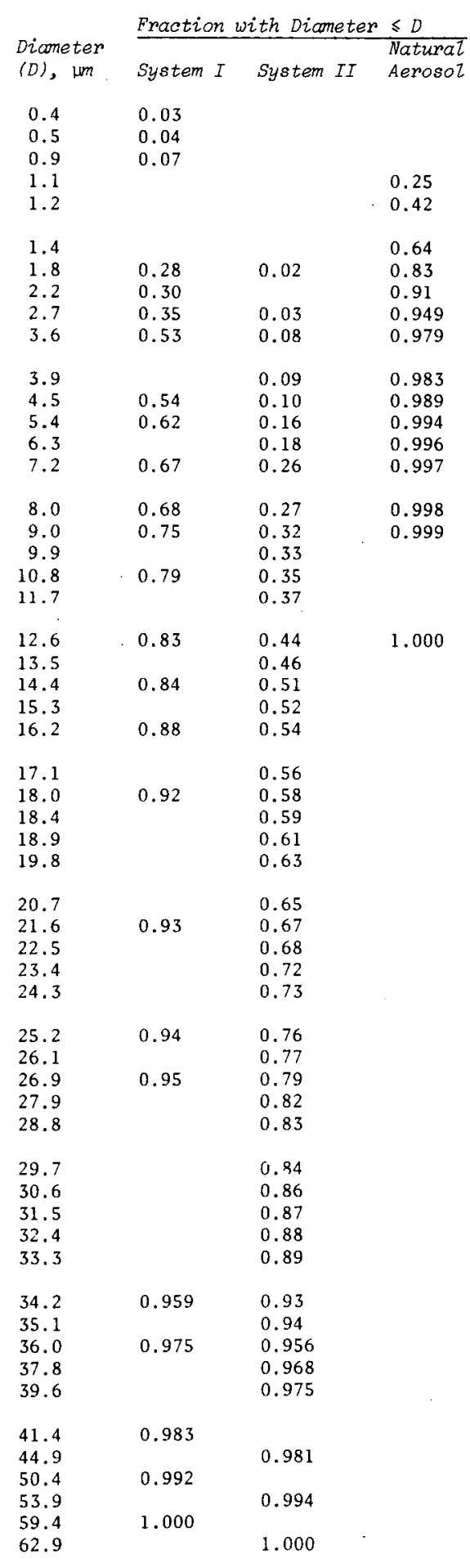

a. Natural aerosols in continental air near the surface; particle diameter (D) of greater than $1 \mu \mathrm{m}$. 
To illustrate the effect of the sampling points within System II on the size distribution of the particles, four histograms (Figure 3) were constructed for particles collected from Sampling Points A, B, C, and D. The analyzed particles from each sampling point were arranged in order of increasing diameter. The grouping interval selected was the cube root of 10 because of the log-normal nature of the frequency distribution.

For comparison, a cumulative frequency plot was also made of the size distribution of particles in natural atmospheric aerosols.

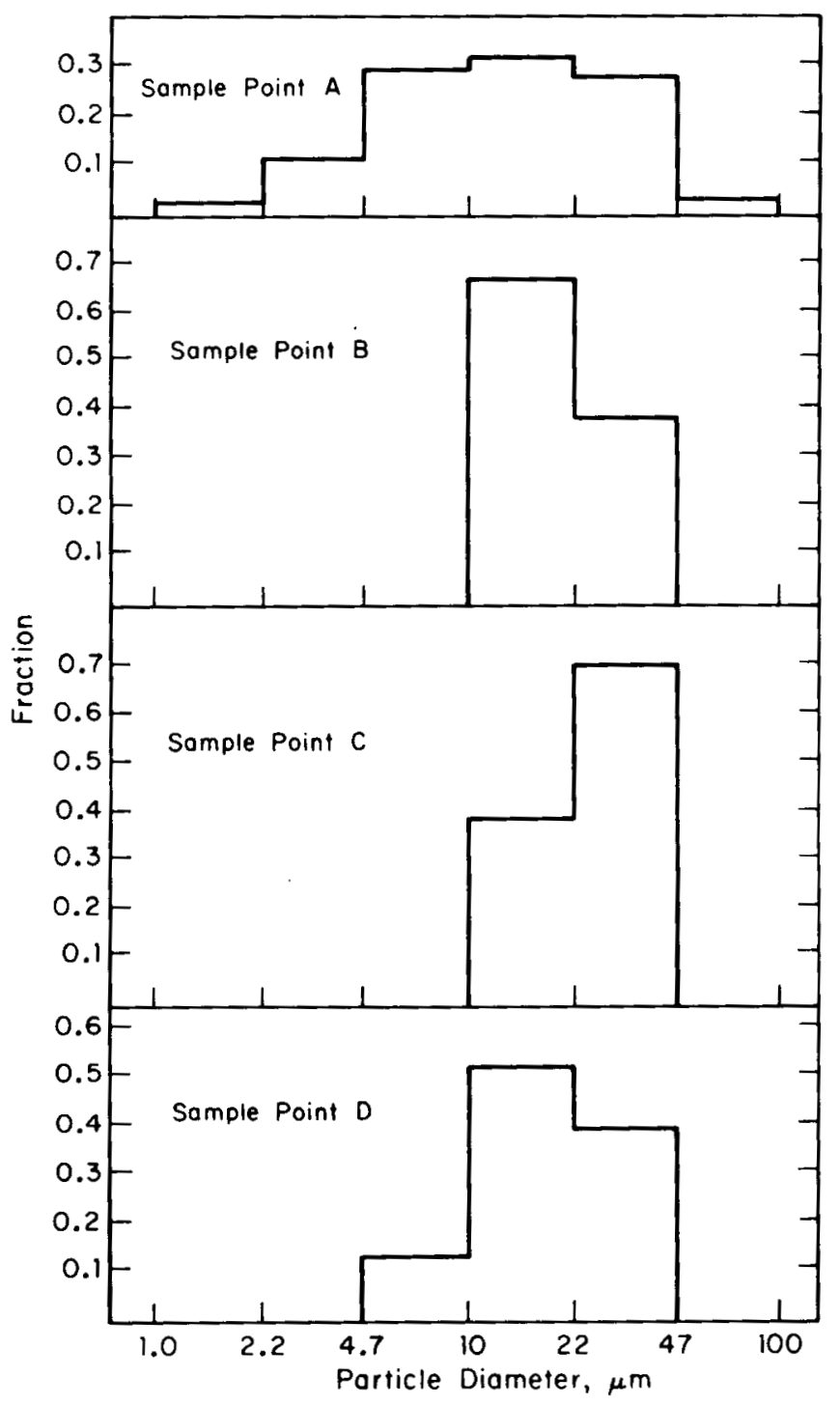

FIGURE 3. Frequency Distribution of Diameters of Particles Collected from System II 
A very simple function that has been used extensively in atmospheric research to express particle size distribution in both natural and polluted atmospheres is

$$
\frac{d N}{d D}=a^{-b}
$$

where $\mathrm{N}$ is the number concentration or total number of particles per unit volume having diameters from the lower limit of definition of aerosols up to diameter $D$ in $\mu \mathrm{m}$. From the relationships

$$
\mathrm{dD}=\mathrm{D} d(\ln \mathrm{D})
$$

and

$$
\ln D=\ln 10 \cdot \log D
$$

the more useful expression

$$
\frac{\mathrm{dN}}{\mathrm{d}(\log \mathrm{D})}=(\ln 10) \mathrm{aD}^{-\mathrm{C}}
$$

is obtained where $c=b-1$, and $d N / d(\log D)$ is called the number distribution. Junge 4 found $c$ to be about 3 over the size range $-0.7<\log \mathrm{D}<1.5$ or $0.2<\mathrm{D}<32 \mu \mathrm{m}$. Integrating the first equation between $D_{O}$ and $D\left(D_{O}<D\right)$ gives

$$
\mathrm{N}=\left[\frac{\mathrm{aD}-\mathrm{C}}{\mathrm{c}}\right]_{\mathrm{D}}^{\mathrm{D}}=\frac{\mathrm{a}}{3}\left[\frac{1}{\mathrm{D}_{\mathrm{O}}^{3}}-\frac{1}{\mathrm{D}^{3}}\right]
$$

Instead of expressing the distribution as the number of particles per unit volume, it can be expressed as a fraction, $F$, of the total number of particles or

$$
F=\frac{N}{N_{T}}=1-\left[\frac{D_{0}}{D}\right]^{3}
$$

where $N_{T}$ is the total number of particles when $D=\infty$, and $N_{T}=$ a/3D 3 . To obtain a reasonable distribution, only those particles which could be easily seen with an optical microscope were included. Thus $D_{0}$ was assumed to be $1 \mu \mathrm{m}$, and Equation 6 can be expressed as

$$
F=1-\frac{1}{D^{3}}
$$


The frequency distribution for natural aerosols with particle diameters between $1 \mu \mathrm{m}$ and $D$, calculated from this expression, is given in Column 2 of Table 4 and plotted in Figure 2.

To see how closely the distribution of particle diameters resembles a log-normal distribution, the assumption was made that the observed diameters represent a sample of a population having a log-normal distribution. The geometric mean diameter, $\bar{D}_{g}$, and geometric standard deviation, $\mathrm{s}_{\mathrm{g}}$, were calculated from these data using equations similar to those given earlier for the geometric mean enrichment factor and geometric standard deviation. These values are given in Table 5. Values for the upper $68.27 \%$ imit for the diameters were calculated from the product of $\bar{D}_{g}$ and $s_{g}$. The best fit log-normal probability curves were plotted on the logarithmic probability graph in Figure 2 by drawing straight lines through coordinates for $\bar{D}_{g}$ and $\bar{D}_{g}{ }^{\cdot} s_{g}$ on the 50.00 and $84.14^{*}$ cumulative percent absissae, respectively.

To determine the degree of asymetry, the skewness (SK) of these frequency distributions was calculated using the relationship

$$
S K=3\left(\frac{\ln \vec{D}_{g}-\ln D_{\text {med }}}{\ln S_{g}}\right)
$$

where $D_{\text {med }}=$ the median diameter. A perfect $10 \mathrm{~g}$-normal distribution has a skewness of zero. If a distribution has a higher tail to the right than to the left, it is positively skewed. Most of the distributions encountered here are negatively skewed; i.e., have higher left-hand tails. Calculated skewness values are given in Table 5 .

TABLE 5

Distributions of Particle Diameters in Systems I and II

$\begin{array}{cllll} & \begin{array}{l}\text { Data } \\ \text { Points, }\end{array} & \begin{array}{l}\text { Geom. Mean } \\ \text { Diameter, }\end{array} & \begin{array}{l}\text { Geom. Std. } \\ \text { Deviation, }\end{array} & \text { Skewness, } \\ \text { System } & N & \bar{D}_{g} & s_{g} & \text { SK } \\ \text { I } & 121 & 4.64 & 2.92 & 0.71 \\ \text { II } & 158 & 13.70 & 2.15^{\circ} & -0.07\end{array}$

$* \quad 50.00+\frac{68.27}{2}$ 


\section{PARTICLE EVALUATION BY PLUTONIUM CONTENT}

Another characteristic studied was the distribution of plutonium among the particles as indicated by the observed number of fission-fragment tracks in the surrounding polycarbonate. Initially, the number of tracks per particle were counted for all plutonium-bearing particles on a filter before any were selected for analysis. Track counts for specific analyzed particles, which would have permitted a correlation of plutonium content with particle size and composition, are therefore not available in this study.

The track distribution among particles from both systems was evaluated in the same way as the particle diameters. The fraction of the particles with the number of tracks equal to or less than a selected number, $T$, are given for Sampling Points $\mathrm{A}, \mathrm{B}$, and $\mathrm{C}$ in Table 6 . Figure 4 is a logarithmic probability plot of cumulative percent of particles from each of these sampling points. Figure 5 is a similar plot for particles from four locations in System I. The calculated geometric mean for the number of fission-fragment tracks per particle, the geometric standard deviation, and the skewness for particles from each sampling point are given in Table 7 . Best fit log-normal probability curves for each distribution are plotted in Figures 4 and 5. For comparison of the track distributions for particles from the various sampling points in System I with those from System II, the probability curve for the track distribution for particles from Sampling Point A in System II is plotted with the distributions from System I in Figure 5.

\section{DISCUSSION}

The most abundant elements in average crustal rock (and soil) are oxygen $(46.60 \%)$, silicon $(27.72 \%)$, aluminum $(8.13 \%)$, iron $(5.00 \%)$, calcium $(3.63 \%)$, sodium $(2.83 \%)$, potassium $(2.59 \%)$, magnesium $(2.09 \%)$, and titanium $(0.44 \%)$. ${ }^{5}$ With the exception of oxygen, which was not detected by electron microprobe analyses, these elements are also found in most inorganic particles (Tables 2 and $\mathrm{A}-1)$. This supports the idea that most plutonium-bearing particles are airborne crustal material to which minute quantities of plutonium have become attached.

of particular interest is the quantity of ${ }^{239} \mathrm{Pu}$ contained on these particles. One femtocurie ( $1 \mathrm{fCi}=10^{-15} \mathrm{Ci}$ ) of ${ }^{239} \mathrm{Pu}$ irradiated under the conditions described here should produce 41 fission-fragment tracks. The minimum detection limit for electron microprobe analysis of plutonium is about 0.2 picograms

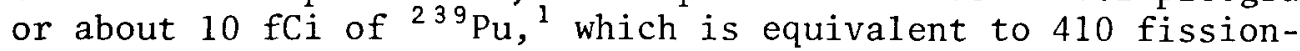
fragment tracks. Because of this relatively low sensitivity of 
TABLE 6

Distribution of Fission Tracks among Plutonium-Bearing Particles Collected from Sampling Points A, B, and C

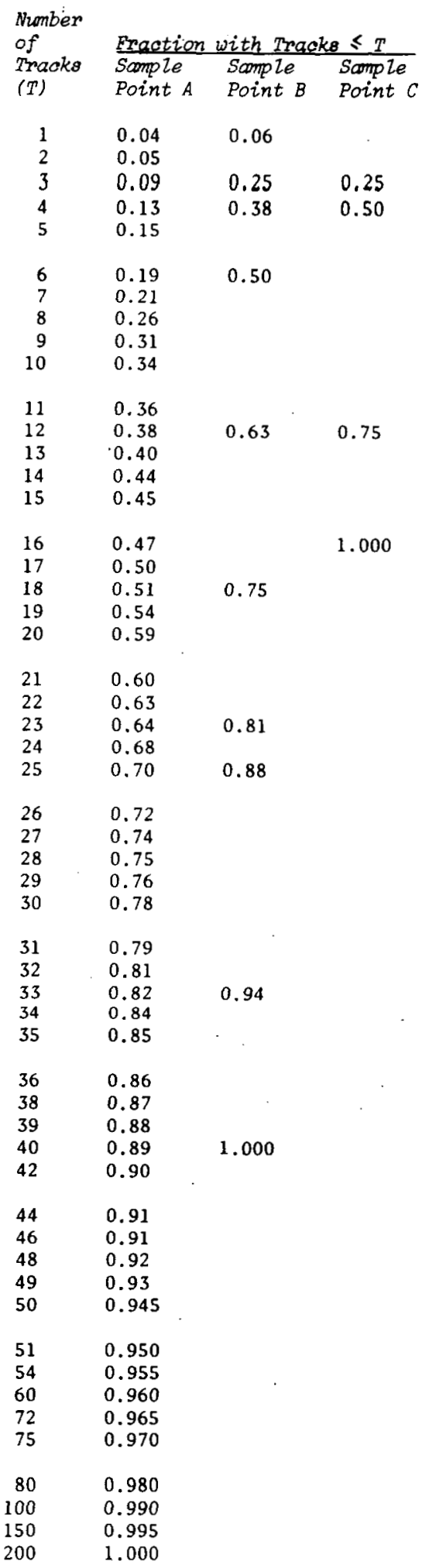




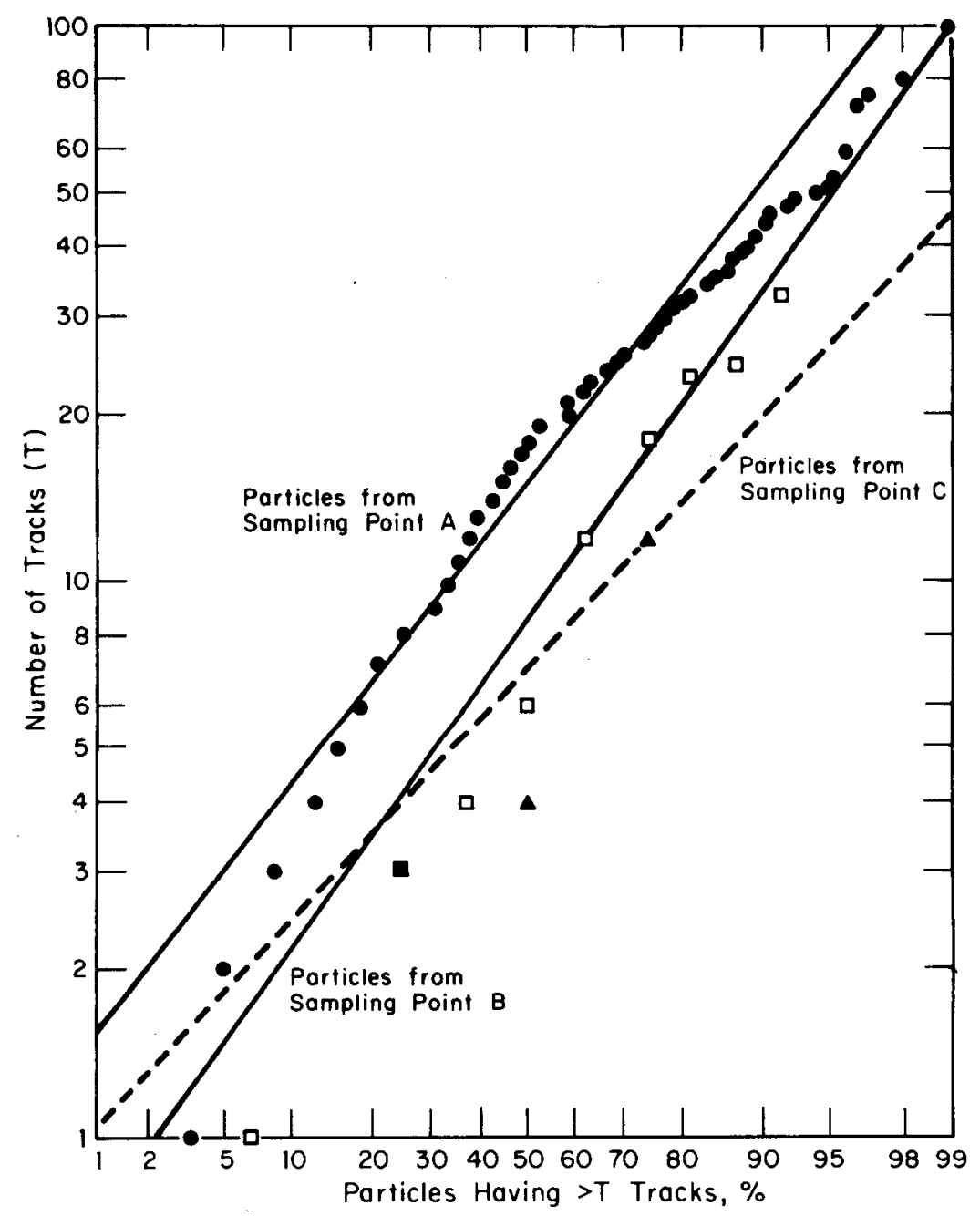

FIGURE 4. Distribution of the Number of Tracks per Particle for Particles Collected from Sampling Points A, $B$, and $C$ in System II

electron microprobe analysis, plutonium could be detected by this method in only one of the 299 particles selected for analysis, even though all the particles produced fission-fragment tracks.

This single particle was a smal1, 1- $\mu$ m-diameter particle, collected from unfiltered wet-cabinet exhaust. It contained $73 \% \mathrm{PuO}_{2}$ by weight (equivalent to $170 \mathrm{fCi}$ of ${ }^{239} \mathrm{Pu}$ ) in combination with $\mathrm{Fe}_{2} \mathrm{O}_{3}$ and mica. ${ }^{1}$

of the major crustal elements listed in Table 2, silicon and iron were the most ubiquitous being found in most particles. 


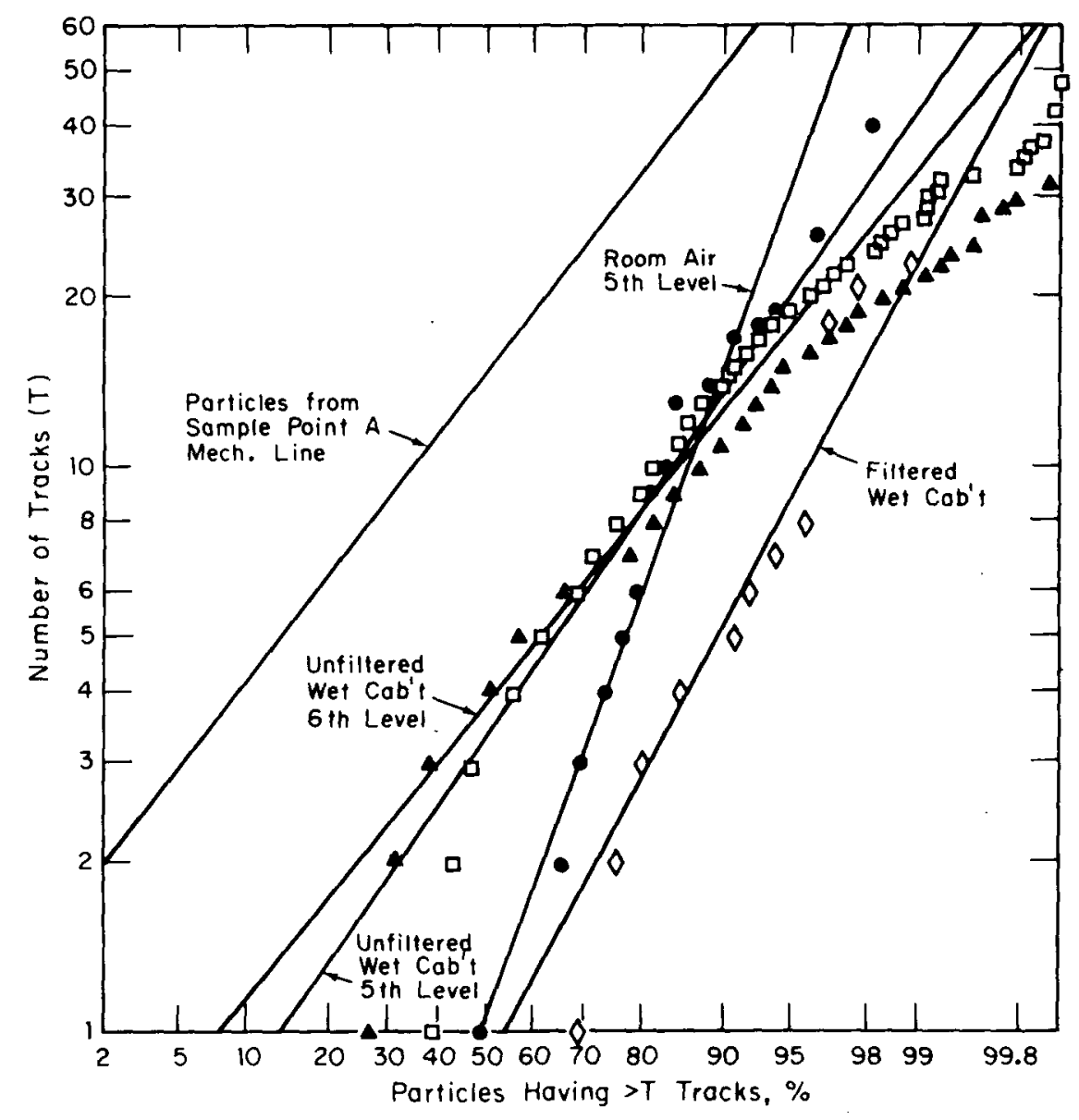

FIGURE 5. Distribution of the Number of Tracks per Particle for Particles Collected from the Mechanical Line (Sampling Point A), Wet Cabinets, and Room Air

The enrichment factor distribution for these elements, however, does not fall within the log-normal distribution for crustal material. For the enrichment factors of an element to match the log-normal distribution of crustal material in aerosols, there should be about $16 \%$ of the enrichment factors of less than one geometric standard deviation, $68 \%$ within one geometric standard deviation of the mean, and another $16 \%$ above one geometric standard deviation. This lack of conformity may result from the low values for the geometric standard deviations of the enrichment factors for these elements in aerosols. By comparison with the enrichment factor distribution of global aerosols, particles in both Systems I and II are depleted in silicon and enriched in iron. 
TABLE 7

Distribution of Fission Tracks among Plutonium-Bearing Particles from Various Sources in Systems I and II

\begin{tabular}{|c|c|c|c|c|}
\hline Source & $\begin{array}{l}\text { Data } \\
\text { Points, } \\
N\end{array}$ & $\begin{array}{l}\text { Geom. Mean } \\
\text { of No. of } \\
\text { Fission } \\
\text { Tracks, } \bar{T}_{a}\end{array}$ & $\begin{array}{l}\text { Geom. Std. } \\
\text { Deviation, } \\
s_{G}\end{array}$ & $\begin{array}{l}\text { Skewne } \\
\text { SK }\end{array}$ \\
\hline \multicolumn{5}{|l|}{ System I } \\
\hline $\begin{array}{l}\text { Unfiltered } 5 \text { th Level } \\
\text { Wet-Cabinet Air }\end{array}$ & 15,987 & 3.76 & 2.56 & -0.20 \\
\hline $\begin{array}{l}\text { Unfiltered 6th Level } \\
\text { Wet-Cabinet Air }\end{array}$ & 7,042 & 3.32 & 2.99 & -0.51 \\
\hline 5th Level Room Air $a$ & 53 & 1.00 & 8.40 & -0.98 \\
\hline Filtered Wet-Cabinet Air ${ }^{a}$ & 98 & 0.87 & 4.14 & -0.29 \\
\hline \multicolumn{5}{|l|}{ System II } \\
\hline Sampling Point A Air & 200 & 14.74 & 2.69 & -0.43 \\
\hline Sampling Point B Air & 16 & 8.34 & 2.90 & -0.07 \\
\hline Sampling Point C Air & 4 & 6.93 & 2.26 & -0.18 \\
\hline
\end{tabular}

a. Values determined graphically.

The enrichment factors for calcium, sodium, potassium, and magnesium closely fit the log-normal distribution of crustal material. Calcium and potassium were negatively skewed in System I and positively skewed in System II. The distribution of magnesium enrichment factors was slightly negatively skewed in both systems, similar to that for crustal material.

Even some of the minor elements have close to log-normal distributions of their enrichment factors. The distribution of enrichment factors for chlorine was nearly log-normal for System I particles, whereas this distribution for System II particles was positively skewed. This variation was possibly caused by using dichloroethane to remove the polycarbonate from these particles rather than using low-temperature oxidation, as was done in System I.

Particles from both systems were enriched in titanium, manganese, chromium, nickel, zinc, and copper. A higher percent of the particles in System I than in System II contained these elements. The most striking example was nickel. While $56 \%$ of the particles from System I contained nickel, only $2 \%$ of those 
in System II did. The chromium and nickel may have come from the $304 \mathrm{~L}$ stainless steel alloy of cabinets and exhaust ducts or the Hastelzoy*-C alloy in the wet cabinets. However, few of the particles contained the proper ratio of chromium-to-nickel found in either alloy. Also, if Hastelloy-C contributed the nickel in the particles, some molybdenum should also have been detected.

A higher percentage of the particles from System II contained sulfur than did particles from System I. In addition, the distribution of the sulfur enrichment factors was log-normal in System II, while that in System I was negatively skewed. Only particles from System II were enriched in phosphorus, barium, and cadmium relative to System I particles. However, the number of particles containing these elements as well as tungsten was so few that a significant comparison can not be made.

The distribution of enrichment factors among particles collected from the different sampling points is shown in Table 4. Enrichment factors for the major elements (i.e., silicon, iron, calcium, potassium, magnesium, and titanium) were similarly distributed in particles from the four sampling points. The only exception was sodium, which was completely lacking in particles collected from Sampling Point D.

Minor elements (such as sulfur, chlorine, chromium, zinc, and copper) were also lacking in particles from Sampling Point D. Phosphorus, manganese, barium, nicke1, tungsten, and cadmium were present in only a few particles, so little significance could be attributed to their distribution among particles from the different sampling points.

The plutonium-bearing particles were larger than natural aerosol particles collected at relatively low altitudes $(<2.3 \mathrm{~km})$ as seen in Figure 2. Those particles collected from System II were larger than those from System I, with geometric mean diameters of $13.7 \mu \mathrm{m}$ and $4.6 \mu \mathrm{m}$, respectively. In System II, particles appeared to increase in diameter as they proceeded from the source to the stack. The histograms in Figure 3 show that, although a larger number of particles from Sampling Points A, B, and D had diameters between 10 and $22 \mu \mathrm{m}$, higher fractions of particles from the more distant points fell within this range. This effect may result from either of two causes: (1) small particles $(<0.5 \mu \mathrm{m})$, which escape filtration, may collide with other particles due to their violent Brownian motion in air to form a flocculated mass or agglomerate downstream from the filter; or (2) larger particles, which escaped during earlier filter change operations, may have selectively settled in the ductwork and later been resuspended.

* Trademark of Cabot Corporation, Boston, Mass. 
The size of the plutonium-bearing particles lies in the range that will be deposited in the lungs. Morrow ${ }^{12}$ estimates that with normal respiration, all particles in a monodispersed aerosol of unit density spheres $37 \mu \mathrm{m}$ in diameter will be deposited in the nasopharyngeal region of the respiratory tract. With larger $(>37 \mathrm{~mm})$ particles, the fraction deposited rapidly decreases. As the diameter decreases, the fraction deposited in the lungs decreases until a minimum of $20 \%$ deposition is reached for particles around 0.1 to $0.2 \mu \mathrm{m}$ in diameter where the particles tend to remain airborne. As the diameters decrease below $37 \mu \mathrm{m}$, a larger fraction is deposited in the tracheobronchial region, until $70 \%$ of the particles $5 \mu \mathrm{m}$ in diameter are deposited in the tracheobronchial region and only $5 \%$ in the nasopharyngeal and 5\% in the alveolar regions. With still smaller particles, the fraction deposited in the tracheobronchial region decreases until at $0.2 \mu \mathrm{m}$ diameter only $10 \%$ are deposited in the tracheobronchial and $10 \%$ in the alveolar regions. For dust particles having a density of around 2.5, this distribution will be shifted toward smaller diameters so that $100 \%$ deposition occurs around $5 \mu \mathrm{m}$.

Particles from all parts of System II also contained on the average more plutonium per particle than those from System I. In System II, the average plutonium content per particle decreases the more distant the sampling point is from the major source. This is shown by the geometric mean number of fission-fragment tracks given in Table 7 . This number decreases from 15 tracks (0.4 fCi) per particle from Sampling Point A to seven tracks (0.2 fCi) per particle from Sampling Point C. The geometric mean number of tracks per particle from unfiltered wet-cabinet air was just over three for both fifth- and sixth-level cabinets (averaging about $0.08 \mathrm{fCi}$ per particle), while that for filtered wet-cabinet air was about one-third of this or almost the same for room air (averaging about $0.02 \mathrm{fCi} /$ particle).

\section{ACKNOWLEDGMENT}

The author gratefully acknowledges the assistance of E. F. Holdsworth and J. T. Armstrong of the Chemistry Department of the Arizona State University in Tempe, Arizona, who performed the electron microprobe analyses. 


\section{APPENDIX: Use of Elemental Enrichment Factors to Express Particle Compositions}

\section{BACKGROUND}

Two recent developments in aerosol studies have provided valuable tools for the analysis of particle composition data. The first is the use of ratios of elemental concentrations called "enrichment factors" to compare aerosol compositions. Begun in the early seventies, this technique has gained wide acceptance in the last few years ${ }^{6-10}$. The second development is the availability of data on the composition of natural aerosols. In the last few months, $\operatorname{Rahn}^{6}$ published a compilation of 104 data sets of trace elements in aerosols along with the geometric mean and geometric standard deviation of the enrichment factors for each of the elements. These data sets were from sampling sites ranging from highly industrialized temperature zones to the tropics and poles, and represent all continents except South America, as well as various marine locations. As a framework from which to view much of the order in atmospheric aerosols, Rahn used the concept of aerosol-crust enrichment factors for the elements. This concept has been applied to analyzing data collected in this study to provide for (a) the intercomparison of the compositions of plutonium-bearing particles with atmospheric aerosols compiled by Rahn and (b) the intracomparison among particles collected from different sampling points.

\section{MICROPROBE ANALYSES OF PARTICLES}

To be comparable, results of microprobe analyses must be expressed as elemental ratios. The reason for this is that not all elements which may be present in an aerosol are detected by microprobe analysis. The microprobe used in this study is quantitative only for elements with atomic numbers greater than 10 . It is only semi-quantitative for oxygen (the most abundant element in crustal material) as well as other major elements of low atomic number such as hydrogen, fluorine, and carbon. Atmospheric aerosols are known to contain, in addition to elements and oxides, carbonaceous material such as sooty carbon and organics and water-soluble ionic material such as sulfate, nitrate, and ammonium ions. Thus elemental weight percents, normalized to 100 based on the elements detected cannot be compared. Even the addition of a hypothetical oxygen concentration, calculated on the supposition that all elements are present as oxides of 
known valence, will still not account for the organic fraction of particles. However, a ratio of the concentrations of one element to another will normally be relatively unaffected by the concentrations of other elements which may be present and thus can be used for comparisons even when a complete analysis of all the elements in an aerosol or single particle is not available.

\section{ENRICHMENT FACTORS}

A dimensionless ratio of elemental concentrations, called the enrichment factor, has been defined as

$$
E F(X)=\frac{(X / \operatorname{Re} f)_{\text {aeroso1 }}}{(X / \operatorname{Re} f)_{\text {source }}}
$$

where $E F(X)$ is the enrichment factor of element $X$ in an aerosol relative to some source material. $X / \operatorname{Ref}$ is the ratio of the concentration of element $X$ to the concentration of the reference element, Ref, in both the aerosol and the source material.

\section{SOURCE MATERIAL}

Elemental ratios in aerosols or in single particles are normalized by dividing them by ratios of the same elements in a standard source material to obtain the enrichment factors. If a particle is composed of the same material as the source, the enrichment factor will be 1.00 for all elements. If the ratio of an element to the reference element is greater or less than the same ratio in the source material, the enrichment factors will be greater or less than 1.00 , and the particle is said to be either enriched or depleted, respectively, in that element.

The most commonly-used crustal source material for continental enrichment-factor calculations is globally-averaged crustal rock. (For marine enrichment-factor calculations, sea salt is used.) The selection of rock may seem strange for there is little doubt that soil rather than rock is the precursor to the crustal aerosol. Some $93 \%$ of the earth's continental surface is covered by soil. ${ }^{11}$ Many of these soils are in states of loose aggregation which can easily be made airborne by the wind. Chemically, however, $\operatorname{Rahn}^{6}$ has found that the composition of the crustal aerosol is not unambiguously that of soil. Elements in natural aerosols with rock-like enrichment factors include $\mathrm{Si}, \mathrm{Fe}, \mathrm{Ca}, \mathrm{K}$, and $\mathrm{Cr}$; those with soil-like enrichment factors are $\mathrm{Ti}$ and $\mathrm{Ba}$. One would expect natural aerosols to be, like soil, depleted in the more soluble elements. Except for glacial activity and to a lesser extent in deserts, physical weathering processes, which ultimately produce 
small particles from boulders, are very slow and are accompanied at all stages by intense chemical weathering. Thus large masses of physically pulverized rock which have not been chemically weathered are not available for aerosol production.

Rahn ${ }^{6}$ speculates that remote continental aerosols are never as depleted in the soluble elements (e.g., $\mathrm{Na}, \mathrm{K}, \mathrm{Ca}$, and $\mathrm{Mg}$ ) as they should be relative to rock (if natural aerosols were purely soil-derived)because of the presence of small amounts of marine aerosol. Soluble elements, especially $\mathrm{Na}$ and $\mathrm{Mg}$, are abundant in the marine aerosol, thus only small amounts of this aerosol in remote continental areas would noticeably raise the proportions of soluble elements in an aerosol collected there.

In addition to the similarity in the elemental composition of aerosol and crustal rock, available analytical data are much less numerous and less reliable for soils, especially for several interesting trace elements which are enriched in aerosols.

For these reasons, the majority of authors who calculate aerosol-crust enrichment factors have chosen one of the several available tables of elemental abundances in average crustal rock. Because the composition of plutonium-bearing particles are compared with data reported by Rahn, ${ }^{6}$ the same crustal-rock composition used by him (that reported by Mason ${ }^{5}$ ) was selected as the source material composition for this work. Column 2 of Table A-1 gives the elemental concentrations in globally-averaged crustal rock for those elements found in plutonium-bearing particles.

\section{REFERENCE ELEMENT}

Of the various elements which seem to be reliably crustderived in aerosols, aluminum, silicon, and iron are generally considered to be the most suitable reference elements. (When sea salt is the source material, the nearly universal choice is sodium.) An acceptable crustal reference element should have high concentrations in rock and soil, very low pollution potential, ease of determination by a number of analytical techniques, and freedom from contamination during sampling. Iron has markedly higher pollution potential than does aluminum, and so is less suited for use with urban or rural aerosols. Silicon is probably the most unambiguous elemental indicator of crustal material. Unfortunately, silicon has been determined in so few aerosol samples that it can not be used as the reference element where comparisons are to be made. Aluminum is a major element $(81,300$ $\mathrm{ppm}$ in rock), wel1-determined by a variety of analytical techniques, and has a minimum of specific pollution sources. 


\section{TABLE A-1.}

Elemental Concentrations in Average Crustal Rock and Geometric Mean Enrichment Factors of Various Aerosols

\begin{tabular}{|c|c|c|c|c|c|c|c|}
\hline EZement & $\begin{array}{l}\text { Conc., } \\
\text { ppm }\end{array}$ & $\begin{array}{l}\text { Global } \\
\overline{E F}_{g} / s_{g}\end{array}$ & $\begin{array}{l}\text { GLobal } \\
\overline{E F}_{g}\end{array}$ & $\begin{array}{l}\text { GLobal } \\
\overline{E F}_{g} \cdot s_{g}\end{array}$ & $\begin{array}{l}\text { Remote } \\
\text { Marine } \\
\overline{E F}_{g}\end{array}$ & $\begin{array}{l}\text { Remote } \\
\text { Conti- } \\
\text { nental } \\
\overline{E F}_{g}\end{array}$ & $\begin{array}{l}\text { Urban } \\
\overline{E F}_{g}\end{array}$ \\
\hline $\mathrm{Si}$ & 277,200 & 0.62 & 0.79 & 1.01 & 0.7 & 0.7 & 0.79 \\
\hline A1 & 81,300 & 1.00 & 1.00 & 1.00 & 1.0 & 1.0 & 1.00 \\
\hline $\mathrm{Fe}$ & 50,000 & 1.05 & 2.06 & 4.06 & 2.5 & 1.5 & 2.2 \\
\hline $\mathrm{Ca}$ & 36,000 & 1.15 & 2.84 & 7.04 & 8 & 1.5 & 2.9 \\
\hline $\mathrm{Na}$ & 28,300 & 0.64 & 4.44 & 30.8 & $10^{2}-10^{3}$ & 0.4 & 1.81 \\
\hline K & 25,900 & 0.99 & 1.98 & 3.98 & 6 & 1.5 & 1.63 \\
\hline $\mathrm{Mg}$ & 20,900 & 0.64 & 2.38 & 8.90 & $10^{1}-10^{2}$ & 0.7 & 2.0 \\
\hline $\mathbf{T i}$ & 4,400 & 1.01 & 1.39 & 1.92 & 1.2 & 1.2 & 1.63 \\
\hline $\mathrm{P}$ & 1,050 & 0.79 & 2.63 & 8.71 & - & - & 2.6 \\
\hline Mn & 950 & 1.45 & 3.91 & 10.5 & 3 & 2 & 3.2 \\
\hline $\mathrm{Ba}$ & 425 & 2.61 & 5.50 & 11.6 & - & $\sim 2$ & 4.8 \\
\hline $\mathbf{S}$ & 260 & 228 & 608 & 1620 & - & - & 490 \\
\hline $\mathrm{C} 1$ & 130 & 100 & 740 & 5470 & $10^{4}-10^{5}$ & 40 & 300 \\
\hline $\mathrm{Cr}$ & 100 & 2.50 & 8.11 & 26.3 & 20 & 6 & 6.2 \\
\hline $\mathrm{Ni}$ & 75 & 8.74 & 31.9 & 116 & 100 & 50 & 10.8 \\
\hline $\mathrm{Zn}$ & 70 & 79.7 & 257 & 832 & 400 & 80 & 300 \\
\hline $\mathrm{Cu}$ & 55 & 34.0 & 102 & 304 & 150 & 20 & 149 \\
\hline$w$ & 1.5 & 4.89 & 19.1 & 74.3 & - & - & 11.0 \\
\hline $\mathrm{Cd}$ & 0.2 & 274 & 1920 & 13400 & 5000 & 2000 & 940 \\
\hline
\end{tabular}


Thus for this work, enrichment factors for element $X$ in most particles were calculated using

$$
E F(X)=\frac{(X / A 1)_{\text {particle }}}{(X / A 1)_{\text {rock }}}
$$

with aluminum as the reference element and average crustal rock as the source material. However, 18 particles from System I and 37 from System II contained no aluminum. Thus the enrichment factors had to be based on silicon rather than aluminum where

$$
\begin{aligned}
\mathrm{EF}(\mathrm{X})= & \frac{(\mathrm{X} / \mathrm{Si}) \text { particle }}{(\mathrm{X} / \mathrm{Si})_{\text {rock }}} \cdot \frac{(\overline{\mathrm{Si}} / \mathrm{A} 1) \mathrm{g} \text { aerosol }}{(\mathrm{Si} / \mathrm{A} 1) \text { rock }}= \\
& 0.79 \frac{(\mathrm{X} / \mathrm{Si})_{\text {particle }}}{(\mathrm{X} / \mathrm{Si})_{\text {rock }}}
\end{aligned}
$$

(The second set of ratios is the geometric mean of the global aerosol-crust enrichment factor explained in the next section.)

Using these two relationships, the enrichment factors were calculated from the elemental weight percents obtained for 115 particles in System I and 156 particles in System II. Six sma11 (0.5 to $3.6 \mu \mathrm{m}$ diameter) iron particles in System I and two particles ( $215 \mu \mathrm{m}$ diameter containing $\mathrm{K}, \mathrm{Cr}$, and $\mathrm{Fe}[1: 3: 3]$ ) from Sample Point A of System II contained neither aluminum nor silicon and were thus not included in the study.

\section{COMPARATIVE AEROSOL DATA}

To compare the elemental composition of plutonium-bearing particles with that of atmospheric aerosols, enrichment factors calculated for elements in these particles were grouped according to data supplied by Rahn ${ }^{6}$ for aerosols. In his report, trace element concentrations in aerosols from 104 published and unpublished data sets were used to calculate enrichment factors. From the enrichment factors in each data set, the geometric mean enrichment factor $\left(\overline{\mathrm{EF}}_{\mathrm{g}}\right)$ and geometric standard deviation $\left(\mathrm{s}_{\mathrm{g}}\right)$ of the logarithmic frequency distributions of enrichment factors were calculated for each element using the following formulae:

$$
\overline{\mathrm{EF}}_{g}=\exp \left[\frac{1}{N} \sum_{i=1}^{N} \ln \mathrm{EF}_{i}\right]
$$

and 


$$
s_{g}=\exp \left\{\left[\frac{1}{N-1} \sum_{i=1}^{N}\left(1 n E_{i}-1 n \overline{E F}_{g}\right)^{2}\right]^{\frac{1}{2}}\right\}
$$

where $\mathrm{N}=$ the number of data points

$E F_{i}=$ the enrichment factor of the ith point

The geometric mean enrichment factors obtained by Rahn ${ }^{6}$ for 19 elements are given in Table A-1 for global, remote marine, remote continental, and urban aerosols. The geometric means of the global aerosol enrichment factors include data from all points and may be weighted too heavily toward cities, but they can serve as a useful first approximation to a general aerosol. The urban enrichment factors are geometric means for 29 cities. The enrichment factors for remote continental and remote marine areas were read from the enrichment-factor plots and are therefore somewhat subjective.

To obtain the lower and upper limits for $68.27 \%$ of the enrichment factors closest to the geometric mean, values for $\overrightarrow{\mathrm{EF}}_{\mathrm{g}} / \mathrm{s}_{\mathrm{g}}$ and $\overrightarrow{\mathrm{EF}}_{\mathrm{g}} \cdot \mathrm{s}_{\mathrm{g}}$, respectively, were calculated using global values. (When describing concentrations at selected statistical levels remote from a mean, the $s_{g}$ is a multiplier or divider of the $\overline{\mathrm{EF}}_{\mathrm{g}}$, whereas its counterpart Gaussian standard deviation functions as an increment to the arithmetic mean. This is a consequence of the fact that multiplying and dividing values is equivalent to adding and subtracting their logarithms.) The results from these calculations are also given in Table A-1. 


\section{REFERENCES}

1. S. Marshall Sanders, Jr. Compositions of Airborne PlutoniumParticles from a Plutonium Finishing Operation. USERDA Report DP-1445, E. I. du Pont de Nemours and Company, Savannah River Laboratory, Aiken, S.C. (1976).

2. H. Yakowitz, R. L. Myklebust, and K. F. J. Heinrich. FRAME: An On-Line Correction Procedure for Quantitative Electron Probe Microanalysis. National Bureau of Standards Technical Note 796, National Bureau of Standards, Washington, D. C. (1973).

3. John T. Armstrong and Peter R. Buseck. "Quantitative Chemical Analysis of Individual Microparticles Using the Electron Microprobe: Theoretical." Anal. Chem. 47, 2178-2192 (1975).

4. C. E. Junge. Handbook of Geophysics and Space Environments. pp. 5-23. S. L. Valley, editor. Air Force Cambridge Research Laboratories, Office of Aerospace Research, US Air Force, Cambridge, Mass. (1965).

5. B. Mason. Principles of Geochemistry, 3rd ed., p 45. John Wiley and Sons, New York, N. Y. (1966).

6. Kenneth A. Rahn. The Chemical Composition of the Atmospheric Aerosol. Technical Report, Graduate School of Oceanography, University of Rhode Island, Kingston, R.I. (1976).

7. Kenneth A. Rahn. Sources of Trace EZements in Aerosols - An Approach to Clean Air. Ph.D. Thesis, University of Michigan, Ann Arbor, Mich. (1971). Xerox University Microfilms (Order No. $72-4956)$.

8. William H. Zoller, E. S. Gladney, and Robert A. Duce. "Atmospheric Concentrations and Sources of Trace Metals at the South Pole." Science 183, 198 (1974).

9. Robert A. Duce, Gerald L. Hoffman, and William H. Zoller. "Atmospheric Trace Meta1s at Remote Northern and Southern Hemisphere Sites: Pollution or Natural?" Science 187, 59 (1975). 
10. H. E. Neustadter, J. S. Fordyce, and R. B. King. "Elemental Composition of Airborne Particulates and Source Identification: Data Analysis Techniques." Air PolZution Control Assoc. 26 (11), 1079 (1976).

11. E. L. Kothny. "The Three-Phase Equilibrium of Mercury in Nature." Trace Elements in the Environment, pp. 48-80. Advances in Chemistry Series 123, American Chemical Society, Washington, D. C. (1973) .

12. P. E. Morrow. "Evaluation of Inhalation Hazards Based Upon the Respirable Dust Concept and the Philosophy and Application of Selective Sampling." Amer. Ind. Hygiene Assoc. J. 25 (2) 213 (1964). 